\title{
Localization of nuclear materials in large concrete radioactive waste packages using photofission delayed gamma rays
}

\author{
Manon Delarue $^{1}$, Eric Simon ${ }^{1 *}$, Bertrand Pérot ${ }^{1}$, Pierre-Guy Allinei ${ }^{1}$, Nicolas Estre ${ }^{1}$, Daniel Eck ${ }^{1}$, Emmanuel \\ Payan $^{1}$, David Tisseur ${ }^{2}$, O. Gueton ${ }^{3}$, Denise Ricard ${ }^{4}$ and Johann Collot ${ }^{5}$ \\ ${ }^{1}$ CEA, DES, IRESNE, DTN, SMTA, Nuclear Measurement Laboratory, F-13108 St Paul-lez-Durance, France \\ ${ }^{2}$ CEA, DES, IRESNE, DER, SPESI, Instrumentation Sensors and Dosimetry Laboratory, F-13108 St Paul-lez- \\ Durance, France \\ ${ }^{3}$ CEA, DES, IRESNE, DTN, F-13108 St Paul-lez-Durance, France \\ ${ }^{4}$ ANDRA, French National Radioactive Waste Management Agency, F-92298 Châtenay-Malabry, France \\ ${ }^{5}$ Université Grenoble Alpes, CNRS, Grenoble INP, LPSC-IN2P3, 38000 Grenoble, France \\ *Corresponding author: eric.simon@cea.fr
}

\begin{abstract}
The characterization of radioactive waste packages is mandatory for their transport, interim storage and final disposal. In this framework, the Nuclear Measurement Laboratory of CEA DES IRESNE Institute, at Cadarache, France, uses a high-energy electron linear accelerator (LINAC) to produce an interrogating bremsstrahlung beam with endpoint energies ranging from 9 to $21 \mathrm{MeV}$ to perform X-ray imaging and high-energy photon interrogation on large concrete packages. In particular, highenergy photon beam induces photofission reactions in both fissile $\left({ }^{235} \mathrm{U},{ }^{239} \mathrm{Pu},{ }^{241} \mathrm{Pu}\right)$ and fertile $\left({ }^{238} \mathrm{U},{ }^{240} \mathrm{Pu},{ }^{232} \mathrm{Th}\right.$, etc.) actinides possibly present in the radioactive waste. In order to assess their mass, we use delayed gamma rays emitted by their photofission products, which are measured with a $50 \%$ relative efficiency High-Purity Germanium (HPGe) detector. Actinide differentiation, which is important for the fissile mass estimation, is based on the ratios of gamma rays emitted by different photofission products and requires appropriate corrections for the gamma attenuation in concrete. To this aim, we report here a localization method of point-like nuclear materials in the concrete matrix, based on the differential attenuation of several gamma rays emitted by a same photofission product. We use here the 1435.9 and $2639.6 \mathrm{keV}$ lines of ${ }^{138} \mathrm{Cs}$, with both experimental data and MCNP numerical simulations to determine the $(r, \theta)$ coordinates of nuclear materials. Then, the depth inside the concrete matrix, which is determined with a precision of a few percent, mainly depending on counting statistics on 1435.9 and $2639.6 \mathrm{keV}$ net peak areas, is used to correct for the different gamma ratios used in the actinide identification method. Experimental tests with uranium samples have been performed to validate the localization method.
\end{abstract}

Keywords - Photofission, Uranium, Delayed gamma rays, Bremsstrahlung, MCNP, Concrete matrix, Nuclear material localization

\section{INTRODUCTION}

$\mathrm{T}$ HE characterization of radioactive waste packages is a major challenge that has to be addressed to ensure the safety during their management (transport, interim storage, final repository). To that extent, the nuclear material content must be accurately evaluated. Among the active nondestructive methods implemented to obtain characterization information in the case of large and dense packages, such as concrete drums [1] -[5], Active Photon Interrogation with highenergy X-rays (i.e. photofission) is the only one that could bring sufficient information on the nuclear material content inside the package. This interrogating technique relies on the fact that all actinides undergo fission when using photons of energy higher than $6 \mathrm{MeV}$. Coupled with the detection of delayed gamma rays emitted by photofission products, this method has the potential to evaluate the actinide mass present in a package, and possibly to separate fertile and fissile isotopes (for example ${ }^{235} \mathrm{U}$ and ${ }^{238} \mathrm{U}$ ) using a discrimination signal based on their delayed gamma rays.

The potential of analyzing the delayed gamma ray signal following fission to obtain an actinide identification information has already been demonstrated in the past. Hollas et al. [6] and Beddingfield et al. [7] have reported the use of delayed gamma-ray ratios for actinide differentiation, respectively for photofission and thermal neutron fission. Also, experimental work conducted by Gmar et al. [8] highlighted variations in the delayed gamma-ray emissions for uranium samples of different enrichments. Further investigation made by Carrel et al. [1] brought information about the delayed gamma emission following photofission in mixed samples of uranium. Besides, the uranium isotopes differentiation in an $870 \mathrm{~L}$ waste drum by using delayed gamma-ray ratios has already been investigated experimentally with a mockup package [1] and by using Monte-Carlo simulations in the work of Simon et al. [5] .

We present the first steps in the development of a method 
using photofission as a probe to assess the nuclear material content in large volume hydrogenous radioactive waste drums. We propose to exploit gamma-ray ratios of some photofission products emitting multiple gamma rays (such as ${ }^{138} \mathrm{Cs},{ }^{142} \mathrm{La}$, ${ }^{135} \mathrm{I}$, etc.) as attenuation indicators to estimate the depth at which nuclear materials are located inside the radioactive waste package. To that extent, a concrete matrix slice of dimension representative of an $870 \mathrm{~L}$ waste package is used to test a localization technique with uranium samples. The localization of actinides is an essential step in the characterization method to apply attenuation corrections. It avoids the need to use only close-in-energy gamma rays for the actinide identification. Once the actinide location is obtained, the attenuation corrections according to the depth of nuclear materials in the package, also known as matrix and localization effect corrections, are needed for the final assessment of their mass. Accordingly, we propose in this work a first overview of the gamma-ray attenuation correction based on the localization results obtained from the relative attenuation signal.

This paper presents the experimental setup deployed at CEA Cadarache (France) using a high-energy electron linear accelerator (LINAC) in the CINPHONIE irradiation cell [9] to interrogate uranium samples placed in a concrete matrix, and measure the photofission delayed gamma rays with a HighPurity Germanium detector (HPGe).

\section{MATERIALS AND METHODS}

\section{A. Experimental setup}

The electron beam accelerated by the LINAC impinges a $5 \mathrm{~mm}$ thick tungsten target to produce an interrogating bremsstrahlung photon beam, the endpoint energy of which can be modulated from 9 to $21 \mathrm{MeV}$. The pulse frequency is up to $200 \mathrm{~Hz}$ with a $4 \mu$ s pulse width and a peak current of $100 \mathrm{~mA}$ in the target. The dose rate at $1 \mathrm{~m}$ from the tungsten target in the beam axis can reach up to $60 \mathrm{~Gy} / \mathrm{min}$. A $20 \mathrm{~cm}$ thick lead collimator with a rectangular aperture allows to focus the beam on a slice of the radioactive waste package. The collimator is surrounded by $20 \mathrm{~cm}$ thick polyethylene blocks and a cadmium layer of $2 \mathrm{~mm}$ is added at the front face in order to limit the photoneutron flux produced in the tungsten target and in the lead collimator by $(\gamma, n)$ reactions of the bremsstrahlung high energy photons [10] . The LINAC and the collimator surrounded by the neutron shielding are shown in Fig. 1.

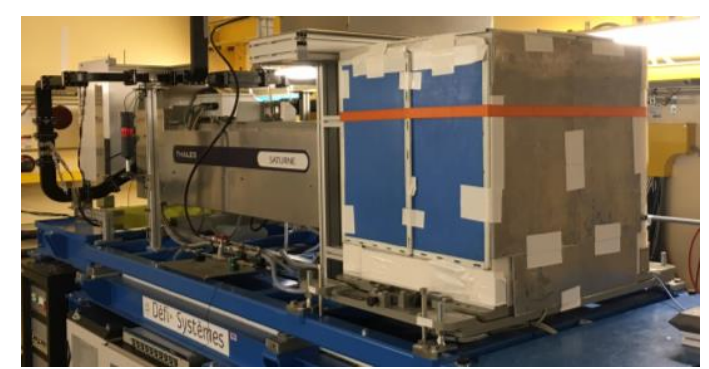

Fig. 1. SATURNE LINAC with its neutron shielding housed in the CINPHONIE casemate.
A remotely controlled mechanical bench, usually dedicated to high-energy photon imaging of waste drums [11], transfers the concrete mock-up slice (Fig. 2a) from the irradiation position to the counting position, which is distant from the LINAC to limit fast photoneutron damages to the HPGe crystal. Delayed gamma rays are recorded with a $50 \%$ relative efficiency n-type coaxial HPGe detector (ORTEC GMX50-83-A-PL) equipped with a transistor-reset preamplifier. Acquisition is performed with a LYNX Digital Signal Analyzer driven by the Genie2000 software (MIRION Technologies), which also allows gamma spectra analysis. Dead-time is taken into account with the livetime correction method. The energy resolution is $2.0 \mathrm{keV}$ (FWHM) at the $1.33 \mathrm{MeV}$ gamma line of ${ }^{60} \mathrm{Co}$. In addition to the abovementioned distance to the LINAC, the detector is shielded by lead and polyethylene to limit neutron damages to the germanium crystal.

The localization technique is tested with two uranium samples described in Table I.

TABLE I

URANIUM SAMPLES CHARACTERISTICS

\begin{tabular}{|c|c|c|}
\hline Sample & $\begin{array}{l}\text { Depleted Uranium } \\
\text { (DU) }\end{array}$ & Highly Enriched Uranium (HEU) \\
\hline Mass & $>100 \mathrm{~g}$ & $>1 \mathrm{~g}$ \\
\hline $\begin{array}{l}\text { Enrichment } \\
\left({ }^{235} \mathrm{U} \text { content }\right)\end{array}$ & $0.3 \%$ & $>90 \%$ \\
\hline Composition & $\begin{array}{l}\text { Metallic uranium } \\
\left(\rho=18.96 \mathrm{~g} . \mathrm{cm}^{-3}\right)\end{array}$ & $\begin{array}{c}\text { Metallic uranium core } \\
\left(\rho=18.96 \mathrm{~g} . \mathrm{cm}^{-3}\right) \text { held between } 2 \\
\text { Zircaloy sheets }\left(\rho=6.56 \mathrm{~g} \cdot \mathrm{cm}^{-3}\right)\end{array}$ \\
\hline Dimension & $1 \mathrm{~cm}$ thickness & $<1 \mathrm{~mm}$ thickness \\
\hline
\end{tabular}

The uranium samples are placed inside a concrete matrix slice of density $2.25 \mathrm{~g} . \mathrm{cm}^{-3}, 1 \mathrm{~m}$ diameter and $15 \mathrm{~cm}$ height, with an external $4 \mathrm{~mm}$ stainless steel strap, shown in Fig. 2a. The matrix contains holes of different diameters where the samples can be inserted, as described in Fig. 2b.
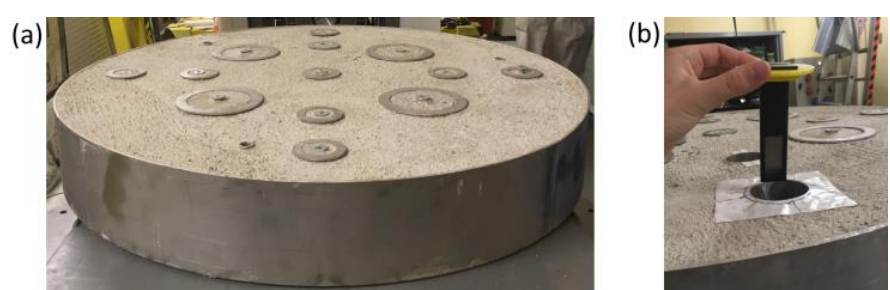

Fig. 2. (a) Overview of the concrete matrix slice of $1 \mathrm{~m}$ diameter (b) Uranium sample in its holder inserted in the matrix hole.

\section{B. Localization method}

In heterogeneous packages such as technological waste, the localization of nuclear materials is crucial for a precise characterization of actinides. The method presented in this paper considers a unique point-like uranium sample inserted in the concrete matrix, inside a hole whose center is located at $40 \mathrm{~cm}$ from the matrix center. The resulting concrete thickness between the sample and the periphery of the concrete slice is at least $7.2 \mathrm{~cm}$. The concrete slice is irradiated with the LINAC photon beam in front of the sample during $2 \mathrm{~h}$. Then, the mechanical bench transfers the concrete matrix from the irradiation position to the counting position in $22 \mathrm{~s}$, while realizing a $45^{\circ}$ rotation. This rotation increases the concrete thickness crossed by delayed gamma rays emitted by 
photofission products (see Fig. 3, counting position 1). After a 45 min acquisition, a backward $45^{\circ}$ rotation puts back the uranium sample in front of the HPGe detector (see Fig. 3, counting position 2 , which is the same as during irradiation), and delayed gamma rays are counted during a few hours (precise acquisition times are given in Table II).

TABLE II

EXPERIMENTAL IRRADIATION AND COUNTING TIMES

\begin{tabular}{cccc}
\hline \hline Sample & $\begin{array}{c}\text { Irradiation } \\
\text { time }\end{array}$ & $\begin{array}{c}\text { Counting time in } \\
\text { Position } 1\end{array}$ & $\begin{array}{c}\text { Counting time in } \\
\text { Position 2 }\end{array}$ \\
\hline DU & $2 \mathrm{~h}$ & $45 \mathrm{~min}$ & $1 \mathrm{~h} 17 \mathrm{~min}$ \\
$\mathrm{HEU}$ & $2 \mathrm{~h}$ & $43 \mathrm{~min}$ & $20 \mathrm{~h} 26 \mathrm{~min}$ \\
\hline \hline
\end{tabular}

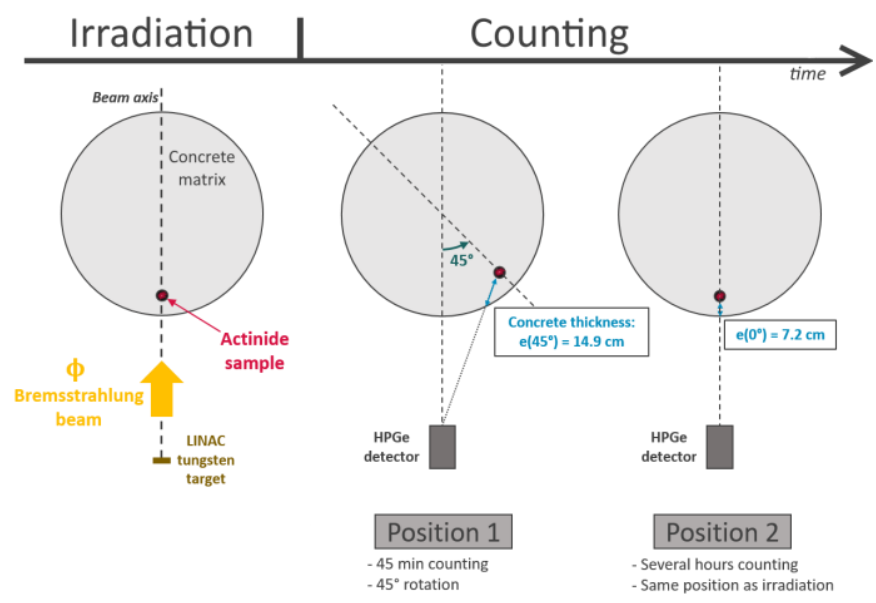

Fig. 3. Experimental steps of the localization method of a point-like uranium sample in a concrete matrix.

The delayed gamma spectra are analyzed with Genie2000 software to extract the net peak areas of the photofission products of interest. For the localization, we are interested in the ratio of two gamma rays emitted by a same photofission product to exploit the differential attenuation of its gamma rays at different energies, when crossing different thicknesses of concrete. The localization combines experimental data with Monte-Carlo simulations performed with MCNP 6.1 computer code [12] . Simulations of a point-like photon source emitting the selected gamma rays are performed for any $(r, \theta)$ position inside the concrete matrix. A point detector (F5 tally) located in front of the HPGe detector estimates the flux of gamma rays of each energy reaching the entrance window, as seen in Fig. 4.

The ratio of these fluxes is evaluated for each $(r, \theta)$ coordinates so as to estimate the "distortion degree" of gamma attenuation (see the map in further Fig. 6). The "distortion" of the ratio is defined as its normalization to the theoretical gamma-ray ratio without attenuation (i.e. without the concrete matrix, see the text above Fig. 6), which only depends on emission intensity and detection efficiency of the gamma rays of interest. The final step is to compare experimental gammaray ratios in positions 1 and 2 with the MCNP distortion map to find the location of the sample in the concrete matrix.

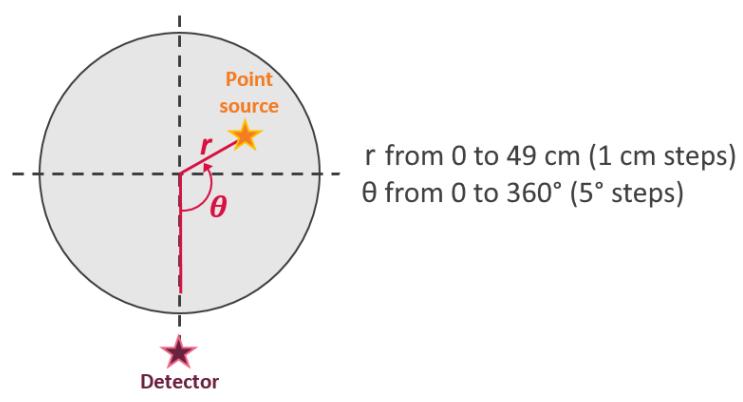

Fig. 4. Principle of the MCNP simulation of the gamma-ray ratio distortion

\section{DATA ANALYSIS AND RESULTS DISCUSSION}

\section{A. Uranium samples localization}

Ref. [10] reports delayed gamma-ray spectra obtained with a similar setup on the bare uranium samples (without the concrete matrix), and presents usable peaks of some photofission products in view to localize actinides. Given acquisition times shown in Table II, especially $45 \mathrm{~min}$ in the first position, ${ }^{138} \mathrm{Cs}$ is a particularly suitable photofission product because of its half-life $T_{1 / 2}=2004.6 \mathrm{~s}$. For the localization, we selected the $1435.9 \mathrm{keV}$ and $2639.6 \mathrm{keV}$ gamma rays, with respective intensities of $76.3 \%$ and $7.63 \%$ [13] . These peaks shown in Fig. 5, for the depleted uranium sample, are well above the active background (i.e. concrete matrix irradiated without uranium sample).

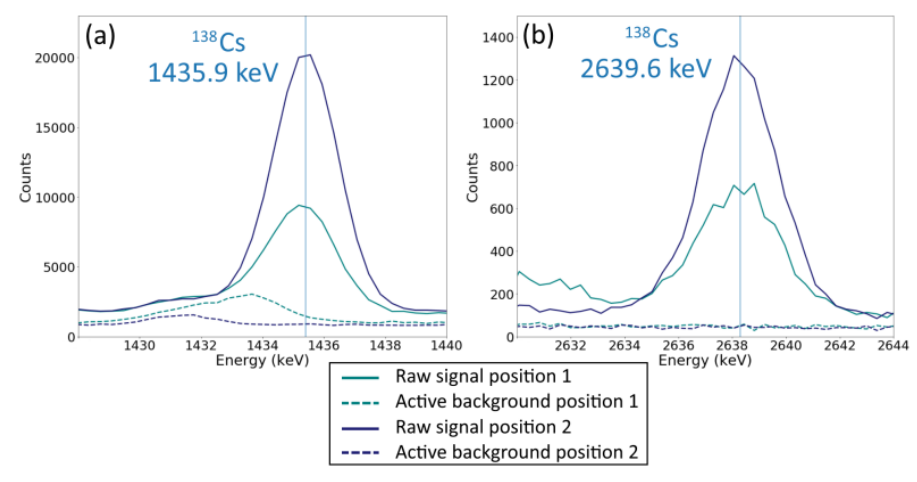

Fig. 5. $1435.9 \mathrm{keV}$ and $2639.6 \mathrm{keV}$ peaks of ${ }^{138} \mathrm{Cs}$ for the DU sample in the concrete matrix and in the two counting positions (and active background).

The net peak areas for the two samples in each position are listed in Table III.

TABLE III

${ }^{138}$ CS GAMMA-RAY NET PEAK AREAS FOR THE DU AND HEU SAMPLES

\begin{tabular}{cccc}
\hline \hline Sample & $\begin{array}{c}\text { Gamma-ray } \\
\text { energy (keV) }\end{array}$ & Position 1 & Position 2 \\
\hline \multirow{2}{*}{ DU } & 1435.9 & $53847 \pm 549$ & $131812 \pm 1471$ \\
& 2639.6 & $5972 \pm 279$ & $11069 \pm 243$ \\
\multirow{2}{*}{ HEU } & 1435.9 & $8257 \pm 341$ & $34528 \pm 1833$ \\
& 2639.6 & $760 \pm 37$ & $2832 \pm 280$ \\
\hline \hline
\end{tabular}

From the net peak areas, the distortion of the measured ratio in each position, due to gamma-ray attenuation, is defined as:

$$
D_{i}=\frac{N_{1}}{N_{2}} \times \frac{I_{2}}{I_{1}} \frac{\varepsilon_{2}}{\varepsilon_{1}}
$$


Where:

- $\quad D_{i}$ is the $1435.9 \mathrm{keV} / 2639.6 \mathrm{keV}$ ratio distortion factor in position $i$,

- $\quad N_{1}$ and $N_{2}$ are the net peak areas of the gamma-ray lines at $\mathrm{E}_{1}=1435.9 \mathrm{keV}$ and $\mathrm{E}_{2}=2639.6 \mathrm{keV}$,

- $\quad I_{1}$ and $I_{2}$ are the emission intensities of the gamma rays, respectively 0.763 and 0.0763 ,

- $\varepsilon_{1}$ and $\varepsilon_{2}$ are respectively the intrinsic detection efficiencies of the gamma rays of energies $E_{1}$ and $E_{2}$. They are determined via simulation and for the two gamma rays of ${ }^{138} \mathrm{Cs}, \frac{\varepsilon_{1}}{\varepsilon_{2}}=1.60$.

Once the experimental distortion factor is obtained in the two positions, it can be compared to the ratio distortion map built from MCNP simulations, covering the full area of the concrete matrix as shown in Fig. 6. The brightest color corresponds to the minimum attenuation and the darkest color to the maximum attenuation and maximum ratio distortion, i.e. the case where the gamma rays cross $1 \mathrm{~m}$ of concrete. The scale from 0 to 1 is obtained by rescaling the ratio distortion at every position by considering that the minimum attenuation corresponds to 1 (the real value is 0.905 ) and the maximum attenuation to 0 (the real value is 0.046 ).

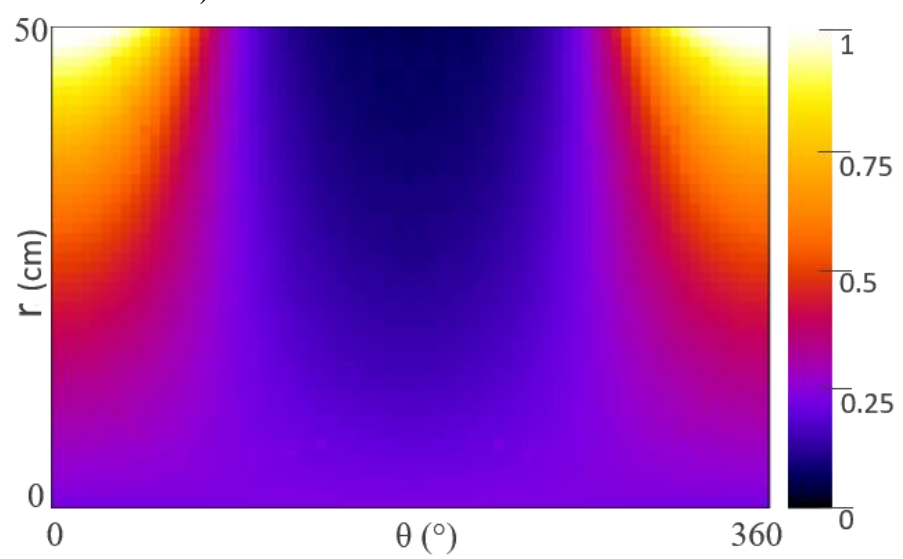

Fig. 6. Distortion map of the $1435.9 \mathrm{keV} / 2639.6 \mathrm{keV}$ gamma-ray ratio $\left({ }^{138} \mathrm{Cs}\right)$, see text for details.

Then, the locations corresponding to the measured ${ }^{138} \mathrm{Cs}$ ratio distortion factor in positions 1 and 2 are determined on the simulated ratio distortion map of Fig. 6. The positions for which the experimental and simulated ratio distortions are in good agreement are represented by the orange and yellow tracks in Fig. 7, respectively for positions 1 and 2 , in case of the DU sample. The location of the sample corresponds to the intersection of these tracks and is represented by the blue dot.

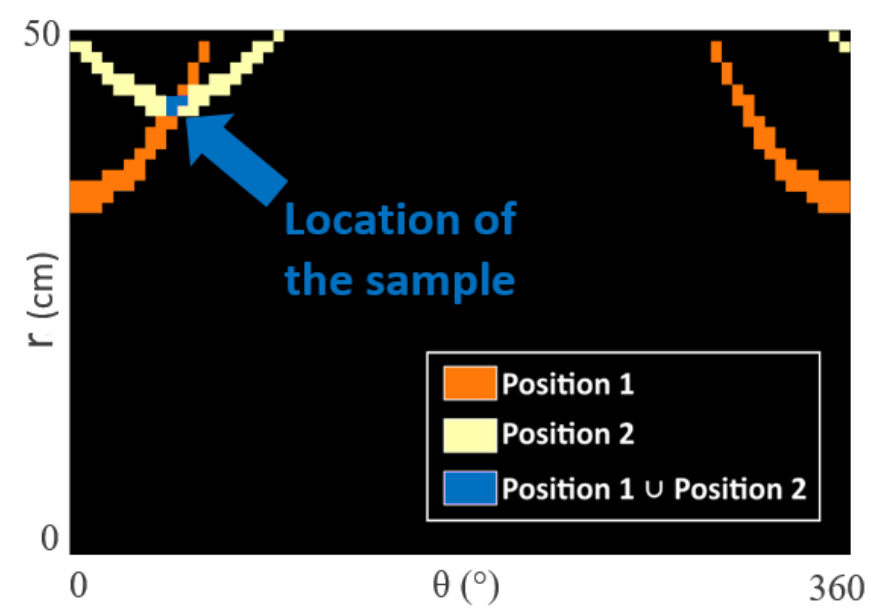

Fig. 7. Sample location from the ratio distortion in the two positions for the DU sample.

Finally, the localization results are compared to the real position of the samples, see Table IV. The uncertainty on the localization, mainly due to counting statistics and photon attenuation in concrete (related to its density), are discussed in section III.B. The estimation of the sample radius is very close to the real position for both DU and HEU samples, within $1 \mathrm{~cm}$. Concerning the angle, it is also very close for the DU sample, but the discrepancy is quite large for the smaller HEU sample due to a poor counting statistics (see Table III).

TABLE IV

LOCALIZATION RESULTS FROM THE ANALYSIS OF THE 1435.9 KEV/2639.6 KEV ${ }^{138}$ CS RATIO DISTORTION

\begin{tabular}{ccc}
\hline \hline Sample & $\begin{array}{c}\text { Real position } \\
(\mathrm{r}, \theta)\end{array}$ & $\begin{array}{c}\text { Localization result } \\
(\mathrm{r}, \theta)\end{array}$ \\
\hline DU & $43 \mathrm{~cm}, 45^{\circ}$ & $\begin{array}{c}(42 \pm 1.5) \mathrm{cm},(47 \pm 10)^{\circ} \\
(43 \pm 3) \mathrm{cm},(33 \pm 17)^{\circ}\end{array}$ \\
\hline HEU & & \\
\hline \hline
\end{tabular}

\section{B. Localization method sensitivity}

In order to test the sensitivity of the localization to the gamma-ray ratios in the two measurement positions, mainly due to counting statistics fluctuations, we varied them independently between $-25 \%$ and $+25 \%$. For instance, the $(r, \theta)$ coordinates are calculated from the gamma-ray ratios measured with the DU sample in the two angular positions $1\left(\mathrm{R}_{1}\right)$ and 2 $\left(R_{2}\right)$. The effect of $a \pm 25 \%$ variation of $R_{1}$ and $R_{2}$ on $r$ and $\theta$ is reported in Fig. 8 and Fig. 9, respectively. Parameters $r$ and $\theta$ have very different sensitivities to ${ }^{138} \mathrm{Cs}$ gamma-ray ratio variations: radius $\mathrm{r}$ has a low sensitivity with a maximum deviation of $-22 \%$ (with $-25 \%$ on $\mathrm{R}_{1}$ and $\mathrm{R}_{2}$ ) but $\theta$ can change up to $230 \%$ (with $+25 \%$ on $\mathrm{R}_{1}$ and $-25 \%$ on $\mathrm{R}_{2}$ ). 


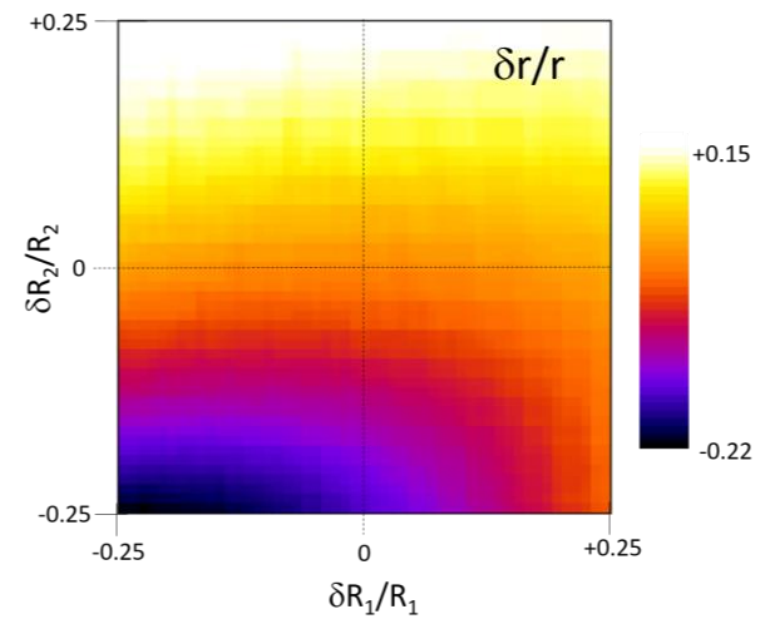

Fig. 8. Effect of the $1435.9 / 2639.6 \mathrm{keV}$ gamma-ray ratio variations, in positions 1 and $2\left(R_{1}\right.$ and $R_{2}$, respectively), on the sample radius $r$.

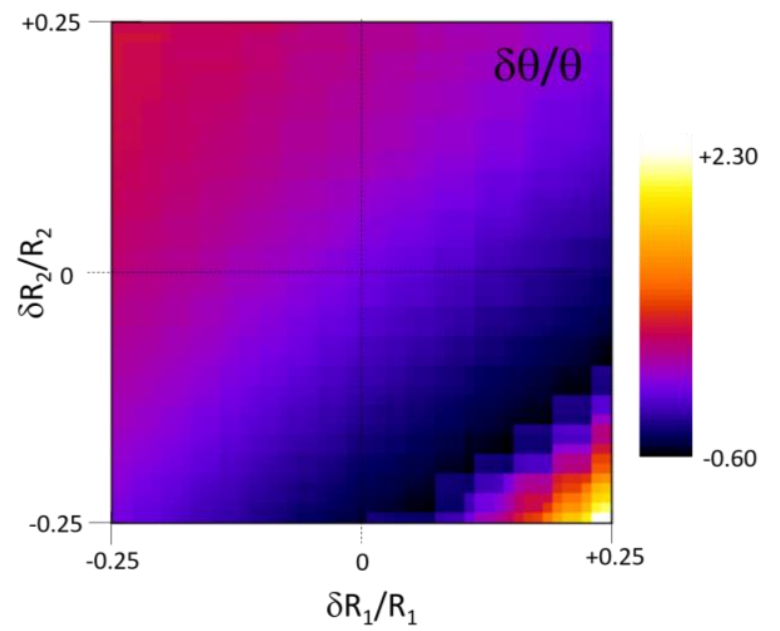

Fig. 9. Angle parameter $\theta$ sensitivity to the gamma-ray ratio variations.

On the other hand, we studied the effect of the uncertainty on gamma attenuation, which can be due to the precision on nuclear data (mass attenuation coefficients), concrete composition and density. We grouped these causes of uncertainty in a study with large density variations. The distortion map used for the location determination (Fig. 6) was calculated with a density of $2.25 \mathrm{~g} . \mathrm{cm}^{-3}$ for the concrete matrix, and we varied it here between $-50 \%$ and $+50 \%$ around this value. Fig. 10 shows the relative deviations of $r$ and $\theta$ as a function of the variability of concrete density in the model.

Globally, $r$ and $\theta$ are not very sensitive to concrete density when using the $1435.9 \mathrm{keV} / 2639.6 \mathrm{keV}$ ratio of ${ }^{138} \mathrm{Cs}$. The localization error is the largest when the simulated density is underestimated compared to the real value. An underestimation of $50 \%$ of the concrete density (i.e. 1.12 instead of $2.25 \mathrm{~g} . \mathrm{cm}^{-3}$ ) induces a $17 \%$ error on $\mathrm{r}$ and $40 \%$ on $\theta$, while a $50 \%$ overestimation (3.37 instead of $2.25 \mathrm{~g} . \mathrm{cm}^{-3}$ ) produces only a $6.2 \%$ error on $r$ and $11.2 \%$ on $\theta$.
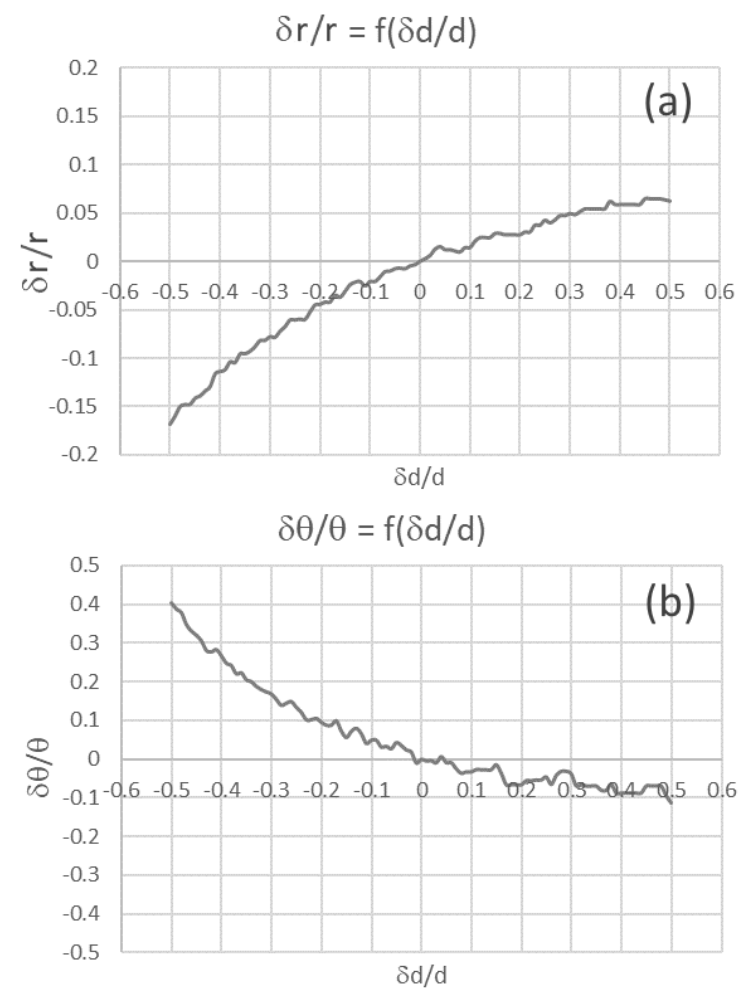

Fig. 10. Sensitivity of (a) $r$ and (b) $\theta$ parameters as a function of concrete density variability.

The localization sensitivity is thus primarily driven by the statistical uncertainty of the gamma-ray ratios measured in the two angular positions. In addition, it is worth mentioning that the determination of $\theta$, which is more sensitive than $r$ to statistical fluctuations, does not affect the quantification of the photofission rate in the sample in view of its mass assessment. Indeed, the package will be rotated during irradiation and only the knowledge of $r$ is crucial to calculate the photofission rate in nuclear materials. The knowledge of $\theta$ is more important for the delayed gamma-ray detection step, in view to position the point-like nuclear material sample in front of the detector after its localization, and for the gamma detection efficiency calculation necessary to estimate the actinides activity or mass. The identification of actinides (e.g. uranium enrichment) based on gamma-ray ratios of different photofission products also requires a gamma attenuation correction using this localization.

\section{Gamma-ray ratio corrections in view of actinides identification}

The localization providing the depth at which the actinides are located in the concrete matrix, a correction factor can be calculated for any measured gamma ratio used in the actinide differentiation technique. Originally, this method was only based on gamma rays with close energies to avoid differential gamma attenuation [1] , but this correction significantly opens the possibilities with gamma rays having very different energies.

In the experiments, the concrete matrix is surrounded by a $4 \mathrm{~mm}$ layer of stainless steel, which is therefore taken into account in the ratio correction examples detailed hereafter. For gamma rays crossing a concrete thickness $e_{c}$ and a stainless steel thickness $e_{s}$, the ratio can be expressed as: 


$$
\begin{aligned}
& R_{12}=\frac{N_{1}}{N_{2}} \\
& =\frac{I_{1} \varepsilon_{1}}{I_{2} \varepsilon_{2}} e^{\left(\left[\left(\frac{\mu}{\rho}\right)_{E_{2}}-\left(\frac{\mu}{\rho}\right)_{E_{1}}\right]_{\text {concrete }} \rho_{c} \cdot e_{c}\right)} e^{\left(\left[\left(\frac{\mu}{\rho}\right)_{E_{2}}-\left(\frac{\mu}{\rho}\right)_{E_{1}}\right]_{\text {steel }} \rho_{S} \cdot e_{S}\right)} \\
& =\frac{I_{1} \varepsilon_{1}}{I_{2} \varepsilon_{2}} e^{\left(\Delta\left(\frac{\mu}{\rho}\right)_{\text {concrete }} \rho_{c} \cdot e_{c}\right)} e^{\left(\Delta\left(\frac{\mu}{\rho}\right)_{\text {steel }} \rho_{s} \cdot e_{s}\right)}=\frac{I_{1}}{I_{2}} \times C
\end{aligned}
$$

Where:

- $\quad R_{12}$ is the ratio of the net peak areas of gamma rays of energies $E_{1}$ and $E_{2}$, respectively $N_{1}$ and $N_{2}$,

- $\quad I_{1}$ and $I_{2}$ are the emission intensities of these gamma rays,

- $\varepsilon_{1}$ and $\varepsilon_{2}$ are the intrinsic detection efficiencies of these gamma rays,

- $\quad\left(\frac{\mu}{\rho}\right)_{E_{i}}$ is the mass attenuation coefficient (in $\mathrm{cm}^{2} \cdot \mathrm{g}^{-1}$ ) of concrete or stainless steel for photons of energy $E_{i}[14]$

- $\quad \rho_{c}$ and $\rho_{s}$ are the densities of concrete $\left(2.25 \mathrm{~g} . \mathrm{cm}^{-3}\right)$ and stainless steel $\left(7.87 \mathrm{~g} . \mathrm{cm}^{-3}\right)$,

- $e_{c}$ and $e_{s}$ are the concrete and stainless steel thicknesses crossed by gamma rays,

- $\quad C$ is the correction factor taking into account the relative detection efficiency of the two gamma rays and the matrix attenuation.

The corrected gamma ratio can be obtained by dividing the measured ratio by the correction factor $C$, calculated with the concrete thickness deduced from actinides localization. We give in Table $\mathrm{V}$ an example of ratio correction for different photofission products of the DU sample in the concrete matrix, for which the stainless steel thickness is $4 \mathrm{~mm}$ and the concrete thickness is $8 \mathrm{~cm}$ (localization result).

\begin{tabular}{|c|c|c|c|c|c|}
\hline $\mathrm{FP}$ & $\begin{array}{c}\text { Gamma-ray } \\
\text { ratio }(\mathrm{keV})\end{array}$ & $\begin{array}{c}\text { Gamma-ray } \\
\text { intensity (\%) }\end{array}$ & $\begin{array}{l}\text { Real } \\
\text { ratio }\end{array}$ & $\begin{array}{l}\text { Measured } \\
\text { ratio }\end{array}$ & $\begin{array}{l}\text { Corrected } \\
\text { ratio }\end{array}$ \\
\hline${ }^{138} \mathrm{Cs}$ & $\begin{array}{l}2218.0 \\
2639.6\end{array}$ & $\begin{array}{c}15.18 \\
7.63\end{array}$ & $1.99 \pm 0.07$ & $1.91 \pm 0.08$ & $2.07 \pm 0.09$ \\
\hline${ }^{135} \mathrm{I}$ & $\begin{array}{l}1131.5 \\
1260.4\end{array}$ & $\begin{array}{l}22.59 \\
28.70\end{array}$ & $0.79 \pm 0.04$ & $0.75 \pm 0.02$ & $0.80 \pm 0.03$ \\
\hline${ }^{142} \mathrm{La}$ & $\begin{array}{l}1545.8 \\
2971.0 \\
2542.7 \\
2971.0\end{array}$ & $\begin{array}{c}2.99 \\
3.13 \\
10.00 \\
3.13\end{array}$ & $\begin{array}{l}0.96 \pm 0.06 \\
3.19 \pm 0.17\end{array}$ & $\begin{array}{l}0.68 \pm 0.10 \\
2.95 \pm 0.41\end{array}$ & $\begin{array}{l}0.95 \pm 0.13 \\
3.16 \pm 0.44\end{array}$ \\
\hline
\end{tabular}

TABLE V

RATIO CORRECTION FOR THE DU SAMPLE IN THE CONCRETE MATRIX

The real ratio corresponds to the intensity ratio of the two considered gamma rays. Its relative uncertainty is calculated as the quadratic combination of the uncertainties on its two gamma-ray intensities, found in JEFF-3.3 database [13]. The relative uncertainty on the measured ratio corresponds to the quadratic combination of the statistical uncertainties on the net peak areas of the gamma rays and on the detector intrinsic efficiency estimated to $2 \%$ with an optimized MCNP model of the HPGe detector. Finally, the relative uncertainty on the corrected ratio is dominated by that of the measured ratio, the uncertainties on the mass attenuation coefficient and concrete thickness being smaller. Finally, the discrepancy between the real and corrected ratios is at most a few percent for the $2218.0 / 2639.6 \mathrm{keV}$ ratio of ${ }^{138} \mathrm{Cs}$, by using the localization provided with the $1435.9 / 2639.6 \mathrm{keV}$ ratio of ${ }^{138} \mathrm{Cs}$.

\section{CONCLUSION}

The localization of point-like nuclear materials characterized by high-energy photon interrogation in large concrete radioactive waste packages is possible using the differential attenuation of gamma rays emitted by a same photofission product, here the 1435.9 and $2639.6 \mathrm{keV}$ lines of ${ }^{138} \mathrm{Cs}$. In particular, the radius is determined with a precision of a few $\mathrm{cm}$, thus giving the depth of nuclear materials inside the concrete matrix.

This information is important to correct for gamma attenuation in the method used to differentiate actinides, which is based on delayed gamma-ray ratios from different photofission products like ${ }^{138} \mathrm{Cs},{ }^{135} \mathrm{I}$ and ${ }^{142} \mathrm{La}$. Thanks to this correction, it will be possible to use delayed gamma rays that are not close in energy, contrary to the original method, which will open the possibilities to improve actinide identification.

Another important task for the characterization of nuclear materials by active photon interrogation is the accurate measurement of the cumulative yields of photofission products, as reported in [10] for ${ }^{235} \mathrm{U}$ and ${ }^{238} \mathrm{U}$. Additional experiments have been recently performed to measure the cumulative photofission yields of ${ }^{239} \mathrm{Pu}$, which will be published soon, as such data are extremely rare so far in the literature.

A series of photofission products liable to allow ${ }^{235} \mathrm{U}$ vs. ${ }^{238} \mathrm{U}$ discrimination in the global photofission signal have been identified in [10]. This work will be continued for uranium vs. plutonium differentiation using our measured uranium and plutonium photofission yields.

\section{ACKNOWLEDGMENT}

The authors would like to thank the French National Radioactive Waste Management Agency (ANDRA) contributing for several years to this research and development activity within a cooperation framework under the COV F32678 DEN4908 - C43R9T5480 contract.

\section{REFERENCES}

[1] F. Carrel, M. Agelou, M. Gmar, F. Lainé, J. Loridon, J.-L. Ma, C. Passard, B. Poumarède, "Identification and Differentiation of Actinides Inside Nuclear Waste Packages by Measurement of Delayed Gammas", IEEE Trans. Nucl. Sci., 57 (5) 2862, 2010.

[2] F. Carrel, M. Agelou, M. Gmar, F. Lainé, "Detection of high-energy delayed gammas for nuclear waste packages characterization”, Nucl. Inst. and Meth. A, vol. 652 (1), pp. 137-139, 2011

[3] T. Nicol, B. Pérot, C. Carasco, F. Brackx, A. Mariani, C. Passard, E. Mauerhofer, J. Collot, "Feasibility study of ${ }^{235} \mathrm{U}$ and ${ }^{239} \mathrm{Pu}$ characterization in radioactive waste drums using neutron-induced fission delayed gamma rays", Nucl. Inst. and Meth. A, vol. 832, pp. 85-94, 2016.

[4] R. De Stefano, C. Carasco, B. Pérot, E. Simon, T. Nicol, E. Mauerhofer, "Feasibility study of fissile mass detection in $870 \mathrm{~L}$ radioactive waste drums using delayed gamma rays from neutron-induced fission", Journ. Radioanal. Nucl. Chem, vol. 322, pp. 1185-1194, 2019.

[5] E. Simon, F. Jallu, B. Pérot, S. Plumeri, "Feasibility study of fissile mass quantification by photofission delayed gamma rays in radioactive waste packages using MCNPX", Nucl. Inst. and Meth. A, vol. 840, pp. 28-35, 2016 . 
[6] C. L. Hollas, D. A. Close, C. E. Moss, "Analysis of fissionable material using delayed gamma rays from photofission”, Nucl. Inst. and Meth. B, vol. 24-25 (1), pp. 503-505, 1987.

[7] D. H. Beddingfield, F. E. Cecil, "Identification of fissile materials from fission product gamma-ray spectra”, Nucl. Inst. and Meth. A, vol. 417, pp. 405-412, 1998.

[8] M. Gmar, J. M. Capdevila, "Use of delayed gamma spectra for detection of actinides (U, Pu) by photofission”, Nucl. Inst. and Meth. A, vol. 422, pp. 841-845, 1999.

[9] B. Pérot, F. Jallu, C. Passard, O. Gueton, P.-G. Allinei, L. Loubet, N Estre, E. Simon, C. Carasco, C. Roure, L. Boucher, H. Lamotte, J. Comte, M. Bertaux, A. Lyoussi, P. Fichet and F. Carrel, "The characterization of radioactive waste: a critical review of techniques implemented or under development at CEA, France", EPJ Nucl. Sci. and Tech. 4 (3), 2018.

[10] M. Delarue, E. Simon, B. Pérot, P.-G. Allinei, N. Estre, E. Payan, D. Eck, D. Tisseur, I. Espagnon, J. Collot, "Measurement of cumulative photofission yields of ${ }^{235} \mathrm{U}$ and ${ }^{238} \mathrm{U}$ with a $16 \mathrm{MeV}$ Bremsstrahlung photon beam", Nucl. Inst. and Meth. A, vol. 1011, https://doi.org/10.1016/j.nima.2021.165598, 2021.

[11] N. Estre, D. Eck, J.-L. Pettier, E. Payan, C. Roure, E. Simon, "HighEnergy X-Ray Imaging Applied to Nondestructive Characterization Characterization of Large Nuclear Waste Drums", IEEE Trans. On Nucl. Sci., vol. 62 (6), pp. 3104-3109, 2015.

[12] Los Alamos National Laboratory, "MCNP $6^{\mathrm{TM}}$ User's Manual”, D. B. Pelowitz, 2013.

[13] A. J. M. Plompen, O. Cabellos, C. De Saint Jean et al., "The joint evaluated fission and fusion nuclear data library, JEFF-3.3", Eur. Phys. J. A, vol. 56, 181, 2020.

[14] J. H. Hubbell, S. M. Seltzer, "Tables of X-Ray Mass Attenuation Coefficients and Mass Energy-Absorption coefficients $1 \mathrm{keV}$ to $20 \mathrm{MeV}$ for Elements $\mathrm{Z}=1$ to 92 and 48 Additional Substances of Dosimetric Interest", National Institute of Standards and Technology, 1995. 